\title{
PEMBELAJARAN MENULIS PARAGRAF DESKRIPSI BERBASIS MIND MAPPING PADA SISWA KELAS VII SMP LABORATORIUM UNDIKSHA
}

\author{
Ida Bagus Putrayasa \\ Jurusan Pendidikan Bahasa dan Sastra Indonesia \\ Universitas Pendidikan Ganesha \\ Singaraja, Indonesia \\ E-mail: ibputra@gmail.com
}

\begin{abstract}
Abstrak
Tujuan penelitian ini untuk mendeskripsikan: (1) pembelajaran menulis paragraf deskripsi dengan model mind mapping pada siswa kelas VII SMP Laboratorium Undiksha Singaraja, (2) kemampuan siswa kelas VII SMP Laboratorium Undiksha Singaraja dalam pembelajaran menulis paragraf deskripsi dengan mind mapping. Rancangan yang digunakan dalam penelitian ini adalah penelitian deskriptif kualitatif.Yang menjadi subjek dalam penelitian ini adalah guru dan siswa kelas VII SMP Laboratorium Undiksha.Objek dalam penelitian ini adalah pembelajaran paragraf deskripsi dengan model mind mapping.Metode yang digunakan untuk mengumpulkan dataadalah metode observasi dan metode tes.Data yang terkumpuldianalisis dengan metode analisis deskriptif kualitatif dan deskriptif kuantitatif.Hasilnya menunjukkan bahwa (1) Pembelajaran menulis paragraf deskripsi dengan model mind mapping yang dilakukan guru sudah sesuai dengan teori yang ada. (2) Kemampuan siswa kelas VII SMP Laboratorium Undiksha dalam menulis paragraf deskripsi tergolong baik. Skor yang diperoleh adalah 78,13 . Walaupun skor yang diperoleh sudah mencapai kategori baik, tampaknya kinerja guru perlu ditingkatkan lagi dengan memberikan latihan-latihan yang lebih intensif, baik dalam membuat mind mapping maupun pengembangannya menjadi paragraf, sehingga tercapai hasil yang maksimal.
\end{abstract}

Kata Kunci: paragraf deskripsi, mind mapping.

\begin{abstract}
This study was aimed at describing (1) an instruction in writing descriptive paragraph using mind mapping model to the seventh grade students of SMP Laboratorium Undiksha Singaraja and (2) the ability of the seventh grade students of SMP Laboratorium Undiksha Singarja in writing descriptive paragraph using mind mapping. This study used descriptive qualitative design. The subjects of this study were teachers and the seventh grade students of SMP Laboratorium Undiksha Singaraja. The object was descriptive paragraph instruction using mind mapping. This study used observation method and test to collect the data. The data gathered were analyzed using qualitative descriptive and quantitative descriptive analysis methods. The results showed that (1) the implementation of the instruction in writing descriptive paragraph using mind mapping model by the teachers has closely followed the existing theory. (2) the ability of the seventh grade students of SMP Laboratorium Undiksha in writing descriptive paragraph using mind mapping fell into category good. The score obtained was 78.13. Although the score obtained has fallen into category good, it seems that the teachers' performance needs to be improved by giving more intensive practices, both in writing mind mapping and in developing it into a paragraph to produce a maximum result.
\end{abstract}

Keywords: descriptive paragraph, mind mapping.

\section{PENDAHULUAN}

Tujuan akhir pembelajaran bahasa Indonesia dititikberatkan pada aspek keterampilan berbahasa. Salah satu aspek keterampilan berbahasa tersebut adalah keterampilan menulis. Keterampilan menulis ini perlu diajarkan sejak awal karena sangat bermanfaat bagi peningkatan aspek intelektual, terutama keterampilan berpikir 
pemelajar. DePorter (2005) mengatakan bahwa menulis merupakan aktivitas seluruh otak, baik belahan otak kanan (emosional) maupun belahan otak kiri (logika) sehingga ketika menulis seluruh belahan otak bekerja secara maksimal.

Karakteristik mata pelajaran bahasa Indonesia dalam KTSP (Kurikulum Tingkat Satuan Pendidikan), khususnya menulis adalah kemampuan mengekspresikan berbagai pikiran, gagasan, pendapat, dan perasaan kepada orang lain yang dituangkan melalui tulisan. Dengan karakteristik tersebut, siswa SMP dituntut untuk mempunyai kemampuan menulis dengan memperhatikan berbagai aspek yang cukup kompleks. Misalnya pilihan bahasa, penguasaan kalimat, dan pengembangan paragraf. Hal ini berarti perkembangan menulis siswa SMP masih perlu diperhatikan. Mengingat pentingnya aktivitas menulis tersebut, keterampilan menulis itu sangat perlu ditingkatkan agar siswa menjadi terampil menulis. Peningkatan keterampilan menulis siswa diyakini dapat mengantarkan siswa mencapai tujuan kurikuler dan pada akhirnya mencapai tujuan pendidikan nasional yang telah ditetapkan.

Keterampilan

merupakan

mengungkapkan gagasan, pendapat, dan perasaan kepada pihak lain melalui bahasa tulis. Pengukuran keterampilan dapat dilaksanakan pada saat berlangsungnya proses pembelajaran yang sengaja dilakukan untuk keperluan itu. Salah satu pengukuran keterampilan menulis yang dilaksanakan pada saat proses belajar mengajar adalah mengarang. Gie (2003) mengatakan bahwa mengarang merupakan segenap rangkaian kegiatan seseorang mengungkapkan gagasan dan menyampaikannya melalui bahasa tulis kepada masyarakat pembaca untuk dipahami.

Weaver (dalam Tarigan, 1986) mengklasifikasikan bentuk menulis menjadi lima, yaitu: narasi, deskripsi, eksposisi, argumentasi, dan persuasi. Paragraf deskripsi adalah paragraf yang menggambarkan suatu benda, tempat, suasana, keadaan dengan kata-kata. Keterampilan menulis paragraf deskripsi merupakan salah satu keterampilan menulis yang penting untuk dikuasai, karena melalui paragraf deskripsi seseorang dapat memberikan gambaran tentang suatu peristiwa atau kejadian. Tujuan penulisan paragraf deskripsi adalah berusaha untuk menggambarkan suatu benda, tempat, suasana, atau keadaan. Seorang penulis paragraf deskripsi mengharapkan pembacanya, melalui tulisannya dapat melihat apa yang dilihatnya, dan dapat mendengar apa yang didengarnya.Menulis paragraf deskripsi memeprlukan pengamatan yang tajam dengan semua alat inderanya, kemudian menuliskannya dengan kata-kata yang tepat atau dengan menggunakan perbandingan yang tepat.

Berdasarkan pengamatan awal di kelas VII SMP Laboratorium Undiksha, peneliti menemukan bahwa siswa masih mengalami kesulitan dalam menulis paragraf deskripsi. Permasalahan yang dihadapi siswa dalam menulis paragraf deskripsi adalah ketidakmampuan siswa menemukan apa yang hendak ditulis, apa topiknya dan bagaimana memulainya. Selain itu, siswa kurang mampu dalam menuangkan ide atau gagasan secara teratur dan logissistematis. Hal ini tampak dari tulisan siswa yang tidak beraturan. Siswa juga belum mampu menggunakan bahasa Indonesia yang baik dan benar. Tampak jelas siswa kurang tepat menggunakan kata dan kalimat dalam tulisannya dan kurang tepat menerapkan kaidah-kaidah ejaan dalam menulis.

Walaupun disadari betul bahwa menulis sangat bermanfaat bagi peningkatan aspek intelektual (keterampilan berpikir), aktivitas menulis ini sangat sulit dilakukan oleh siswa (pemelajar). Kesulitan ini disebabkan oleh beberapa hal. Pertama, secara teoretis, pengajar dalam mengajarkan menulis mulai dengan penjelasanpenjelasan istilah teknis seperti narasi, deskripsi, eksposisi, argumentasi, persuasi, pikiran utama, kalimat utama, pikiran penjelas, dan kalimat penjelas, 
Kemudian dilanjutkan dengan penjelasan syarat-syarat tulisan yang baik, seperti kesatuan, kepaduan (koherensi), dan kecukupan pengembangan. Penjelasan-penjelasan teoretis ini tidak memberikan pemahaman yang memadai tentang menulis.

Kedua, secara metodologis, cara pengajar memberikan topik tulisan. Ada tiga cara yang dilakukan pengajar dalam memberikan topik tulisan, yaitu: (1) menetapkan satu topik untuk ditulis oleh semua pembelajar, (2) menetapkan beberapa topik untuk dipilih salah satu untuk dikembangkan oleh pembelajar, dan (3) membebaskan pembelajar memilih sendiri topik yang akan dikembangkan. Cara (1) dan cara (2) memiliki risiko bahwa pembelajar tidak memiliki pengetahuan yang memadai untuk mengembangkan topik yang disediakan. Cara (3) terkesan memberi peluang kepada pembelajar untuk mengembangkan topik yang paling mereka kuasai. Namun, ada kekhawatiran kalau mereka diberikan kebebasan untuk mengembangkan topik yang paling mereka kuasai. Pikiran yang mereka kembangkan menjadi tulisan tidak terarah, tidak terkontrol, 'liar' karena pikiran mereka memang tidak diarahkan untuk melahirkan gagasangagasan yang logissistematis. Untuk mengantisipasi kekhawatiran tersebut, salah satu model yang ditawarkan pada kajian ini adalah model mind mapping (peta pikiran). Dengan model ini, setelah melakukan pengamatan, siswa dapat memetakan pikirannya atau gagasangagasannya secara logissistematis, dan menuangkannya dalam bentuk tulisan yang koheren. Permasalahannya adalah: (1) Bagaimanakah pembelajaran menulis paragraf deskripsi dengan model mind mapping pada siswa kelas VII SMP Laboratorium Undiksha Singaraja? (2) Sejauh manakah kemampuan siswa kelas VII SMP Laboratorium Undiksha Singaraja dalam pembelajaran menulis paragraf deskripsi dengan mind mapping?
METODE

Rancangan yang digunakan dalam penelitian ini adalah rancangan deskriptif kualitatif dan kuantitatif. Yang menjadi subjek dalam penelitian ini adalah guru dan siswa kelas VII SMP Laboratorium Undiksha dalam pembelajaran paragraf deskripsi dengan model mind mapping. Dalam pembelajaran menulis narasi, salah satu metode yang bisa diterapkan adalah metode mind map. Mind map merupakan salah satu system belajar dan berpikir yang diciptakan pertama kali oleh Tony Buzan dari Inggris. Metode mind map mulai popular sejak awal tahun 1970-an (Sutanto Windura, 2008:13). Menurut Tony Buzan (2007:4) mind map adalah cara termudah menempatkan informasi ke dalam otak dan mengambil ke luar dari otak. Mind map adalah cara mencatat yang kreatif, efektif, dan secara harafiah akan memetakan pikiran-pikiran kita. Sedangkan menurut Doni Swadarma (2013: 3) mind map adalah system berpikir yang terpancar (radiant thinking) sehingga dapat mengembangkan ide dan pemikiran ke segala arah, divergen, dan melihatnya secara utuh dalam berbagai sudut pandang. Waruwu (2010) mengemukakan batasan Mind Mapping atau pemetaan pikiran sebagai berikut: Mind Map adalah cara mengembangkan kegiatan berpikir ke segala arah, menangkap berbagai pikiran dalam berbagai sudut. Mind Map mengembangkan cara pikir divergen, berpikir kreatif. Mind Map adalah alat berpikir organisasional yang sangat hebat. Mind Map dapat diistilahkan sebagai "Pisau Tentara Swiss Otak." Mind Map adalah cara termudah untuk menempatkan informasi ke dalam otak dan mengambil informasi itu ketika dibutuhkan. (http://www.mind-mapping. co.uk, diakses 23/04/2010). Sejalan dengan itu, Astutik (2009) dalam http://ksupointer.com menyatakan bahwa Mind Mapping atau Peta Pikiran adalah metode mempelajari konsep yang ditemukan oleh Tony Buzan. Konsep ini didasarkan pada cara kerja otak kita menyimpan informasi. Hasil penelitian menunjukkan bahwa otak kita 
tidak menyimpan informasi dalam kotakkotak sel saraf yang terjejer rapi melainkan dikumpulkan pada sel-sel saraf yang bercabang-cabang yang apabila dilihat sekilas akan tampak seperti cabang-cabang pohon. Dari fakta tersebut maka disimpulkan apabila kita juga menyimpan informasi seperti cara kerja otak, maka akan semakin baik informasi tersimpan dalam otak dan hasil akhirnya tentu saja proses belajar kita akan semakin mudah. Joomla (2010) dalam http://duniaguru.com. Mengemukakan Mind Mapping atau Peta Pikiran adalah metode mempelajari konsep yang ditemukan oleh Tony Buzan. Konsep ini didasarkan pada cara kerja otak kita menyimpan informasi. Hasil penelitian menunjukkan bahwa otak kita tidak menyimpan informasi dalam kotak-kotak sel saraf yang terjejer rapi melainkan dikumpulkan pada selsel saraf yang berbercabang-cabang yang apabila dilihat sekilas akan tampak seperti cabang-cabang pohon.

Dari fakta tersebut maka disimpulkan apabila kita juga menyimpan informasi seperti cara kerja otak, maka akan semakin baik informasi tersimpan dalam otak dan hasil akhirnya tentu saja proses belajar kita akan semakin mudah. Dari penjelasan diatas, bisa disimpulkan cara kerja Peta Pikiran adalah menuliskan tema utama sebagai titik sentral/tengah dan memikirkan cabang-cabang atau tema-tema turunan yang keluar dari titik tengah tersebut dan mencari hubungan antara tema turunan. Itu berarti setiap kali kita mempelajari sesuatu hal maka fokus kita diarahkan pada apakah tema utamanya, poin-poin penting dari tema yang utama yang sedang kita pelajari, pengembangan dari setiap poin penting tersebut dan mencari hubungan antara setiap poin. Dengan cara ini maka kita bisa mendapatkan gambaran hal-hal apa saja yang telah kita ketahui dan area mana saja yang masih belum dikuasai dengan baik. Masih senada, Anton (2010) mengemukakan Mind Mapping atau Peta Pikiranadalah metode mempelajari konsep yang ditemukan oleh Tony Buzan. Konsep ini didasarkan pada cara kerja otak kita menyimpan informasi. Hasil penelitian menunjukkan bahwa otak kita tidak menyimpan informasi dalam kotak-kotak sel saraf yang terjejer rapi melainkan dikumpulkan pada sel-sel saraf yang berbercabang-cabang yang apabila dilihat sekilas akan tampak seperti cabang-cabang pohon. (http://pkab.wordpress.com/2008/02/29 Sementara itu, objek dalam penelitian ini adalah pembelajaran paragraf deskripsi dengan model mind mapping.

Dalam penelitian ini digunakan dua macam metode untuk mengumpulkan data, yakni metode observasi dan metode tes. Metode observasi digunakan untuk mengumpulkan data proses belajar mengajar dengan model mind mapping. Metode tes digunakan untuk mengumpulkan data kemampuan siswa dalam menulis paragraf deskripsi dengan model mind mapping. Data yang terkumpuldianalisis dengan metode analisis deskriptif kualitatif dan deskriptif kuantitatif.

Kriteria dan pedoman yang digunakan untuk mengukur dan menilai kemampuan menulis paragraf deskriptif siswa adalah sebagai berikut.

Tabel 1. Kriteria Penilaian Paragraf Deskriptif

\begin{tabular}{cccc}
\hline $\begin{array}{c}\text { Rincian } \\
\text { Kemampuan } \\
\text { Menulis }\end{array}$ & Skor & Tingkat & Patokan \\
\hline 26-22 & Baik & Amat Baik & $\begin{array}{l}\text { Amat memahami, amat luas dan } \\
\text { lengkap, serta amat sesuai dengan judul } \\
\text { Memahami, luas, lengkap, serta sesuai } \\
\text { dengan judul meskipun kurang terinci }\end{array}$ \\
Isi & $21-17$ & Sedang & $\begin{array}{l}\text { Memahami secara terbatas, kurang } \\
\text { lengkap, serta kurang sesuai dengan }\end{array}$
\end{tabular}




\begin{tabular}{|c|c|c|c|}
\hline $\begin{array}{l}\text { Rincian } \\
\text { Kemampuan } \\
\text { Menulis }\end{array}$ & Skor & Tingkat & Patokan \\
\hline \multirow{8}{*}{ Bahasa } & & & judul, kurang terinci \\
\hline & $16-13$ & Kurang & $\begin{array}{l}\text { Tidak memahami isi, tidak mengenal, } \\
\text { dan tidak cukup untuk dinilai }\end{array}$ \\
\hline & $25-22$ & Amat Baik & $\begin{array}{l}\text { Amat menguasai bahasa, amat sedikit } \\
\text { kesalahan penggunaan dan penyusunan } \\
\text { kalimat }\end{array}$ \\
\hline & $21-18$ & Baik & $\begin{array}{l}\text { Penggunaan dan penyusunan kalimat } \\
\text { yang sederhana, sedikit kesalahan tata } \\
\text { bahasa yang mengaburkan makna }\end{array}$ \\
\hline & & & \\
\hline & $17-11$ & Sedang & $\begin{array}{l}\text { Kesulitan dalam penggunaan dan } \\
\text { penyusunan kalimat sederhana, } \\
\text { kesalahan yang mengaburkan makna }\end{array}$ \\
\hline & $10-5$ & Kurang & $\begin{array}{l}\text { Tidak menguasai penggunaan dan } \\
\text { penyusunan kalimat, tidak komunikatif, } \\
\text { tidak cukup untuk dinilai }\end{array}$ \\
\hline & 5 & Amat Baik & $\begin{array}{l}\text { Amat menguasai kaidah penggunaan } \\
\text { kata, ejaan, dan tanda baca }\end{array}$ \\
\hline \multirow[t]{5}{*}{ Penulisan } & 4 & Baik & $\begin{array}{l}\text { Menguasai kaidah penulisan kata, ejaan, } \\
\text { dan tanda baca }\end{array}$ \\
\hline & 3 & Sedang & $\begin{array}{l}\text { Kurang menguasai kaidah penulisan } \\
\text { kata, ejaan, dan tanda baca dengan } \\
\text { banyak kesalahan }\end{array}$ \\
\hline & 2 & Kurang & $\begin{array}{l}\text { Tidak menguasai kaidah penulisan kata, } \\
\text { ejaan, dan tanda baca, sulit untuk } \\
\text { dibaca, tidak cukup untuk dinilai }\end{array}$ \\
\hline & $20-18$ & Amat Baik & $\begin{array}{l}\text { Amat teratur dan rapi, amat jelas, amat } \\
\text { kaya akan gagasan, urutan amat logis }\end{array}$ \\
\hline & $17-14$ & Baik & $\begin{array}{l}\text { Teratur dan rapi, jelas, banyak gagasa, } \\
\text { urutan logis }\end{array}$ \\
\hline \multirow[t]{2}{*}{ Organisasi } & $13-10$ & Sedang & $\begin{array}{l}\text { Kurang teratur dan rapi, kurang jelas, } \\
\text { kurang gagasan, urutan kurang logis }\end{array}$ \\
\hline & $9-7$ & Kurang & $\begin{array}{l}\text { Tidak teratur dan rapi, tidak jelas, kurang } \\
\text { gagasan, urutan kurang logis, tidak } \\
\text { cukup untuk dinilai }\end{array}$ \\
\hline
\end{tabular}

Tabel 2. Pedoman Penyekoran Menulis Paragraf Deskriptif

\begin{tabular}{ccc}
\hline No. & Skor & Nilai \\
\hline 1. & $85-100$ & Sangat baik \\
2. & $70-84$ & Baik \\
3. & $55-69$ & Cukup \\
4. & $40-54$ & Kurang \\
5. & $25-39$ & Sangat kurang \\
\hline \multicolumn{2}{c}{ (diadaptasi dari Buku Pedoman StudiJPBSI, 2012) }
\end{tabular}


HASIL DAN PEMBAHASAN

Hasil Kemampuan Awal Siswa dalam Menulis Paragraf Deskripsi

Penelitian deskriptif ini dilakukan

pada siswa kelas VII SMP Laboratorium

Undiksha Singaraja. Sebelum dilakukannya pembelajaran menulis dengan mind mapping, siswa diminta untuk menulis paragraf deskriptif dengan tema bebas yang ditentukan oleh siswa sendiri. Langkah ini dilakukan untuk mendapatkan informasi awal tentang kemampuan menulis siswa.Adapun hasil awal kemampuan menulis siswa kelas VII SMP Laboratorium Undiksha Singaraja dapat dilihat pada Tabel 3 di bawah ini.

Tabel 3. Skor Kemampuan Awal Siswa Kelas VII SMP Lab Undiksha dalam Menulis Paragraf Deskripsi

\begin{tabular}{clcc} 
No. & \multicolumn{1}{c}{ Nama Siswa } & Skor & Predikat \\
1. & Komang Agem Wismanjaya & 66 & Cukup \\
2. & IA. Purnama Sari & 62 & Cukup \\
3. & Luh Ayu Trisna & 66 & Cukup \\
4. & Ketut Bayu Catur P. & 63 & Cukup \\
5. & Bram Mahesa Dana & 60 & Cukup \\
6. & Cintya Devi & 70 & Baik \\
7. & Dewa Ayu Putu Dea Novelia & 63 & Cukup \\
8. & Komang Eswa Pramita & 65 & Cukup \\
9. & Gede Feby Suarjaya P. & 61 & Cukup \\
10. & Kadek Frilla Anggreni & 58 & Cukup \\
11. & Fuyi Gunawan P & 59 & Cukup \\
12. & Ida Bagus Ghana Manuaba & 58 & Cukup \\
13. & Gina Vellina & 58 & Cukup \\
14. & I Gst. Ayu Indira Ardeliani & 58 & Cukup \\
15. & Intan Permata Sari & 61 & Cukup \\
16. & Kadek Ira Adi Saputri & 64 & Cukup \\
17. & Jeevan & 70 & Baik \\
18. & Julian F. & 55 & Cukup \\
19. & Putu Justika Nirmala Ardhiana & 60 & Cukup \\
20. & Putu Lanang Dharma W. & 64 & Cukup \\
21. & Maredith Isabellilah & 55 & Cukup \\
22. & - & - & - \\
23. & Nela Rafaela Budi Frank & 64 & Cukup \\
24. & Nita Siryaningsih & 61 & Cukup \\
& $\quad$ Jumlah & 1.421 & \\
& & 61,78 & Cukup \\
\hline
\end{tabular}

Berdasarkan Tabel 3 di atas, dapat dikatakan bahwa rata-rata kemampuan siswa dalam menulis paragraf deskripsi dengan mind mapping adalah 61,78 . Ini berada pada kategori cukup.Skor rata-rata tersebut menunjukkan bahwa kemampuan menulis siswa masih jauh dari ketuntasan belajar, yakni 70. Ini berarti pula bahwa kemampuan menulis siswa perlu ditingkatkan dengan model pembelajaran yang lebih inovatif, sehingga kemampuan siswa dapat meningkat pula menuju pembelajaran yang tuntas.
Salah satu model yang ditawarkan kepada guru yang mengajar di kelas tersebut adalah model mind mapping. Sebelum proses pembelajaran dilakukan, guru yang bersangkutan diberikan pemahaman terlebih dahulu tentang konsep pembelajaran mind mapping, langkah-langkah pembelajaran menulis dengan mind mapping, dan penerapan mind mapping dalam pembelajaran menulis deskripsi di kelas.

Penerapan model mind mapping ini tidak dimaksudkan untuk memperbaiki kualitas pembelajaran seperti yang dilakukan dalam penelitian 
tindakan kelas.Pembelajaran dengan model mind mapping ini dimaksudkan hanya untuk mendeskripsikan kemampuan siswa kelas VII SMP Laboratorium Undiksha dalam menulis paragraf deskripsi. Adapun tes awal yang diberikan terkait dengan menulis paragraf deskripsi hanya bertujuan untuk mengetahui pengetahuan awal siswa tentang kemampuan menulis siswa. Dengan gambaran pengetahuan awal siswa tersebut, dicobakanlah model pembelajaran mind mapping dalam pembelajaran menulis paragraf deskripsi. Hasilnya dapat dilihat pada uraian berikut.

\section{Hasil Observasi Pembelajaran Menulis Paragraf Deskripsi denganMind Mapping}

Pembelajara menulis paragraf deskripsi dengan model mind mapping yang dilakukan pengajar mengikuti langkah-langkah pembelajaran yang sudah dirancang. Pelaksanaan pembelajarannya dimulai dengan apersepsi yang berkaitan dengan pembelajaran menulis paragraf deskripsi. Pengajar menyampaikan kompetensi dasar dan tujuan pembelajaran yang hendak dicapai. Kompetensi Dasar yang disampaikan pengajar adalah 'menulis hasil observasi dalam bentuk paragraf deskripsi'. Sementara itu, tujuan yang hendak dicapai dalam pembelajaran adalah siswa diharapkan mampu: (a) mendaftar topik-topik yang dapat dikembangkan menjadi paragraf deskripsi, menyusun kerangka paragraf deskripsi, (c) mengembangkan kerangka yang telah disusun menjadi paragraf deskripsi, dan (d) menyunting paragraf deskripsi yang ditulis teman. Terkait dengan penggunaan mind mapping dalam menulis paragraf deskripsi, pengajar tinggal menyesuaikan dengan tujuan pembelajaran yang telah ditentukan.

Memasuki kegiatan inti, pengajar memulai pembelajaran dengan menjelaskan konsep tentang menulis paragraf deskripsi, mind mapping, langkah-langkah membuat mind mapping, dan langkah-langkah pembelajaran menulis paragraf deskripsi dengan mind mapping.Di samping hal pokok tersebut yang dijelaskan, pengajar juga menjelaskan peranti atau alat-alat yang mendukung terwujudnya tulisan yang baik, seperti kalimat dan ejaan. Pengajar juga memberikan contoh mind mapping dan cara mengembangkannya menjadi sebuah paragraf agar pemahaman siswa tentang menulis paragraf deskripsi dengan mind mapping semakin meningkat. Walaupun sudah diberikan contoh mind mapping dan cara mengembangkannya menjadi sebuah paragraf, ada juga beberapa siswa yang masih mengalami kendala dalam praktiknya. Adapun hasil kemampuan siswa dalam menulis paragraf deskripsi dengan mind mapping dapat dilihat pada uraian berikut.

\section{Kemampuan Siswa dalam Menulis Paragraf Deskripsi dengan Mind Mapping}

Kemampuan siswa dalam menulis paragraf deskripsi dengan mind mapping dapat dilihat pada Tabel 4 di bawah ini.

Tabel 4. Skor Kemampuan Siswa dalam Menulis Paragraf Deskripsi dengan MindMapping

\begin{tabular}{|c|l|c|c|}
\hline No. & \multicolumn{1}{|c|}{ Nama Siswa } & Skor & Predikat \\
\hline 1. & Komang Agem Wismanjaya & 86 & Sangat baik \\
2. & IA. Purnama Sari & 73 & Baik \\
3. & Luh Ayu Trisna & 85 & Sangat baik \\
4. & Ketut Bayu Catur P. & 77 & Baik \\
5. & Bram Mahesa Dana & 76 & Baik \\
6. & Cintya Devi & 78 & Baik \\
7. & Dewa Ayu Putu Dea Novelia & 77 & Baik \\
8. & Komang Eswa Pramita & 87 & Sangat baik \\
9. & Gede Feby Suarjaya P. & 77 & Baik \\
10. & Kadek Frilla Anggreni & 76 & Baik \\
\hline
\end{tabular}




\begin{tabular}{|c|l|c|c|}
\hline No. & \multicolumn{1}{|c|}{ Nama Siswa } & Skor & Predikat \\
\hline 11. & Fuyi Gunawan P & 75 & Baik \\
12. & Ida Bagus Ghana Manuaba & 78 & Baik \\
13. & Gina Vellina & 86 & Sangat baik \\
14. & I Gst. Ayu Indira Ardeliani & 77 & Baik \\
15. & Intan Permata Sari & 73 & Baik \\
16. & Kadek Ira Adi Saputri & 79 & Baik \\
17. & Jeevan & 86 & Sangat baik \\
18. & Julian F. & 66 & Cukup \\
19. & Putu Justika Nirmala Ardhiana & 79 & Baik \\
20. & Putu Lanang Dharma W. & 68 & Baik \\
21. & Maredith Isabellilah & - & Cukup \\
22. & - & 85 & - \\
23. & Nela Rafaela Budi Frank & 78 & Sangat baik \\
24. & Nita Siryaningsih & 1.797 & Baik \\
& Jumlah & 78,13 & Baik \\
\hline
\end{tabular}

Berdasarkan Tabel 4 di atas, dapat dipaparkan bahwa kemampuan siswa dalam menulis paragraf deskripsi dengan mind mapping secara umum dapat dikatakan tergolong baik dengan skor rata-rata 78,13 . Kalau dirinci lagi paparan umum tentang perolehan skor kemampuan menulis paragraf deskripsi siswa kelas VII SMP Laboratorium Undiksha tersebut, maka tampak pada Tabel 5 di bawah ini.

Tabel 5. Perolehan Skor dan Persentase Hasil Tulisan Siswa

\begin{tabular}{ccc}
\hline Kriteria & Jml. Siswa & Persentase (\%) \\
\hline Sangat Baik & 6 & 26 \\
Baik & 15 & 65 \\
Cukup & 2 & 9 \\
Kurang & 0 & 0 \\
Sangat Kurang & 0 & 0 \\
Jumlah & 23 & 100 \\
\hline
\end{tabular}

Berdasarkandata pada Tabel 5 di atas, dapat dijelaskan bahwa dari 23 orang siswa kelas VII SMP Laboratorium Undiksha Singaraja yang mengikuti pembelajaran menulis paragraf deskripsi dengan mind mapping ditemukan 6 orang siswa (26\%) memperoleh nilai sangat baik; 15 orang siswa $(65 \%)$ memperoleh nilai baik; 2 orang siswa (9\%) memperoleh nilai cukup. Sementara itu, tidak ada siswa $(0 \%)$ yang memperoleh nilai kurang dan sangat kurang. Berdasarkan persentase tersebut, secara klasikal pembelajaran menulis paragraf deskripsi dengan mind mapping dikatakan berhasil karena $91,30 \%$ siswa memperoleh skor 70 ke atas atau dengan nilai baik dan sangat baik.

Data tersebut menunjukkan bahwa ada perubahan atau peningkatan kemampuan menulis paragraf deskripsi siswa kelas VII SMP Laboratorium
Undiksha dari sebelum dan sesudah dilakukan pembelajaran dengan mind mapping. Rerata skor sebelum diterapkan model mind mapping dalam pembelajaran menulis paragraf deskripsi sebesar 61,78 dan setelah diterapkannya model tersebut rerata skor menjadi 78,13. Ini berarti bahwa terjadi peningkatan skor 16,35.

Di samping terjadi peningkatan skor kemampuan menulis paragraf deskripsi, ditemukan juga beberapa hal terkait dengan kekurangcermatan siswa dalam merumuskan kalimat topik tidak lengkap, penyusunan kalimat tidak lengkap, struktur kalimat tidak efektif, penggunaan tanda baca dan penulisan kata tidak sesuai dengan kaidah. Siswa juga kurang tepat membuat mind mapping sesuai dengan gagasan yang akan dikembangkan dalam tulisannya. Akibat dari kekurangtepatan dalam membuat mind mapping tersebut, 
tersusunlah paragraf deskripsi yang kurang padu. Hal-hal tersebut akan dibahas dalam paparan berikut ini.

Sesuai dengan langkah-langkah pembelajaran menulis dengan model mind mapping, maka yang pertama dibahas dalam bagian ini adalah temuan yang menyangkut bagaimana siswa membuat mind mapping sebagai langkah awal dalam mengembangkan gagasannya. Selanjutnya, dibahas mengenai temuan-temuan lain yang terkait dengan peranti yang digunakan dalam penulisan paragraf deskripsi.

Secara umum, siswa sudah cukup cermat membuat mind mapping karena gagasan-gagasan yang dituangkannya dalam mind mapping tersebut mewakili apa sebenarnya yang dimaksudkan. Siswa sudah fokus pada topik-topik yang dikembangkan dalam mind mapping, sehingga dalam pengembangan gagasannya juga terarah. Hal ini terjadi karena siswa sering mendapat pelatihan membuat mind mapping sebagai salah satu cara dalam mengembangkan gagasannya. Pelatihan-pelatihan untuk mengembangkan gagasan dengan mind mapping perlu juga dilakukan secara benar dengan menggunakan warna yang bervariasi, sehingga hasil yang diperoleh dalam menulis paragraf deskripsi maksimal. Hal ini sesuai dengan apa yang disampaikan oleh Silberman (1996) yang mengatakan bahwa dalam membuat sebuah mind mapping (peta pikiran) sederhana untuk pembelajar sebaiknya menggunakan warna, gambar, atau simbol. Jelaskan bagaimana warna, gambar, atau simbol dalam peta pikiran kita (pengajar) meningkatkan seluruh kerja pikiran (versus pemikiran otak kiri/kanan). Perintahkan pembelajar untuk menyisipkan contoh sederhana dari kehidupan sehari-hari mereka yang dapat mereka buatkan peta pikirannya.

Selanjutnya, Silberman (1996) mengatakan bahwa sebaiknya disediakan kertas, spidol, dan materi sumber lain yang menurut kita akan membantu pembelajar menciptakan peta pikiran yang semarak dan cerah. Tugaskan pembelajar untuk membuat peta pikiran. Sarankan agar pembelajar memulai peta mereka dengan membuat sentra gambar, yang menggambarkan topik atau gagasan utamanya. Doronglah mereka agar memecah keseluruhannya menjadi usur-unsur yang lebih kecil dan menggambarkan unsur-unsur ini di sekeliling peta (menggunakan warna dan grafis). Perintahkan mereka untuk mengungkapkan tiap gagasan menggunakan gambar, dengan menyertakan sedikit mungkin kata-kata. Setelah itu mereka dapat memerincinya di dalam pikiran mereka.

Temuan berikutnya terkait dengan peranti menulis adalah ketidaklengkapan kalimat, terutama unsur-unsur inti kalimat yang terdapat dalam tulisan siswa. Secara umum, kalimat-kalimat yang terdapat dalah tulisan paragraf deskripsi siswa kurang lengkap, hanya terdapat subjek atau predikat saja. Hal ini terjadi karena siswa kurang memahami unsur-unsur apa saja yang harus ada dalam kalimat. Semestinya siswa sudah diberikan pemahaman oleh gurunya tentang unsur-unsur minimal yang harus ada dalam kalimat, yakni unsur subjek dan predikat. Hal ini sesuai dengan pendapat Putrayasa (2012) yang mengungkapkan bahwa dalam sebuah kalimat, unsur minimal yang harus ada adalah unsur inti kalimat, yaitu subjek dan predikat. Unsur-unsur ini memberikan pengertian yang lengkap dalam kalimat. Unsur-unsur ini pula yang bisa dikembangkan dengan objek, pelengkap, ataupun keterangan (adverbial).

\section{SIMPULAN DAN SARAN}

Berdasarkan temuan-temuan dan pembahasan hasil penelitian yang dipaparkan pada Bab sebelumnya, dapat disimpulkan hal-hal sebagai berikut.Pembelajaran menulis paragraf deskripsi dengan model mind mapping yang dilakukan pengajar mengikuti langkah-langkah pembelajaran yang sudah dirancang.

Pembelajaran menulis paragraf deskripsi dengan model mind mapping yang dilakukan guru sudah sesuai 
dengan teori yang ada. Walaupun demikian, masih terdapat beberapa siswa yang mengalami kendala dalam pembuatan mind mapping. Hal ini perlu menjadi perhatian guru dalam membuat mind mapping sebagai landasan mengembangkan gagasan menjadi tulisan yang koheren dan kohesif. Guru perlu memberikan latihan-latihan yang cukup dalam membuat mind mapping dan melatih siswa dalam mengembangkan gagasan menjadi tulisan yang padu.

Kemampuan siswa kelas VII

SMP Laboratorium Undiksha dalam menulis paragraf deskripsi tergolong baik. Skor yang diperoleh adalah 78,13. Walaupun skor yang diperoleh sudah mencapai kategori baik, tampaknya kinerja guru perlu ditingkatkan lagi dengan memberikan latihan-latihan yang lebih intensif, baik dalam membuat mind mapping maupun pengembangannya menjadi paragraf, sehingga tercapai hasil yang maksimal.

\section{DAFTAR PUSTAKA}

Achmad DS. 1992. Pembelajaran Menulis. Bandung: Angkasa

Alwi, Hasan, dkk.2003 Kamus Besar Bahasa Indonesia .Jakarta: Pusat Bahasa

Anton. $2010 . \quad$ dalam http://pkab.wordpress.com

Astutik.2009 dalam http://ksupointer.com: diakses 24 April 2010

Buzan, T. (2007). Alih Bahasa Susi Purwoko. Buku Pintar Mind Map. Jakarta: PT Gramedia Pustaka Utama.

Darmadi, Kaswan. 1996. Keterampilan Menulis . Bandung: Angkasa.

DePorter, B. \& Hernacki, M. (2005). Quantum Learning: Membiasakan Belajar Nyaman dan Menyenangkan. Bandung: Kaifa.

Gie, T.L. (2003). Terampil Mengarang. Yogyakarta: Andi Offset.

Horn, Van. 1988. Tulis Apa yang Kamu Lihat (terjemahan). Jakarta: Rosdakarya.
Ismail, Taufik.1997. "Pemelajaran Menulis Memprihatinkan”. Dalam Mimbar Karya Makassar

Putrayasa, I.B. (2012). Tata Kalimat Bahasa Indonesia. Bandung: PT. Refika Aditama.

Salam.1998."Kemampuan Menulis murid SD Inpres Andi Tonro". Ujung Pandang: Skripsi

Silberman, M.L. (1996). Active Learning: 101 Strategies to Teach Any Subject. Boston: Allyn Bacon.

Sumarmo. 1989. Pembelajaran Menulis di SD Teori dan Aplikasi. Jogjakarta: Gema Media

Swadarma, Doni. 2013. Penerapan Mind Mapping dalam Kurikulum Pembelajaran. Gramedia. Jakarta.

Waruwu, Fidelis E dalam http:www.edutraco.com: dakses tanggal, 1 Mei 2010

Windura, Sutanto (2008). Mind Map Langkah Demi Langkah. Jakarta: Elex media Komputindo. 